\title{
- Motivational and Satisfaction Level Among Medical Teachers in India: A Questionnaire Based Survey

\section{S. Zafar Abbas ${ }^{1}$, Shilpa Khullar ${ }^{2}$, Ankur Sachdeva ${ }^{3}$}

'Associate Professor, Department of Radiodiagnosis, ESIC Medical College \& Hospital, NH-3, NIT, Faridabad, Haryana -121001; ${ }^{2}$ Associate Professor, Department of Physiology, ESIC Medical College \& Hospital, NH-3, NIT, Faridabad, Haryana - 1210o; ${ }^{3}$ Assistant Professor, Department of Psychiatry, ESIC Medical College \& Hospital, NH-3, NIT, Faridabad, Haryana - 121001.

\section{ABSTRACT}

Introduction: Job satisfaction is one of the most widely discussed issues in the organisational behaviour, personnel and human resource management. This study was conducted to determine the level of job satisfaction among medical teaching faculty of a teaching institution. An attempt was made to determine the factors that influence the job satisfaction of the faculty members.

Materials and Methods: 64 faculty members agreed to be a part of the study. It was conducted as an opinion survey based on a pre-structured questionnaire divided into two sections: section 1-socio-demographic features of the subjects and section 2 - divided into 6 sub sections with total 19 statements (S1to S19) exploring different factors. The mean score was calculated for each of the statements.

Results: $68.75 \%$ of the faculty were young ( $<40$ years of age), majority were females $(56.25 \%)$ and were at the rank of assistant professors (68.75\%).Based on the responses to the questionnaire around $61 \%$ of the faculty members were satisfied with their current job. The range of the mean score of the faculty members was from 2.16 to 4.05 . The average mean score for all the statements was 3.47 .

Conclusion: Based on the results of the survey it can be concluded that the faculty seems to be most satisfied with the teamwork and interpersonal relationships within the organisation (S5). The faculty rated their performance to be high as per their job expectations (S-9) and they considered themselves to be well equipped in terms of knowledge and skills as per their job expectations (S-10). They seemed to be most dissatisfied with the performance based incentives given at the college (S-17) and loan facilities offered (S-13) by the organisation.

Key Words: Faculty members, Teaching institution, Job satisfaction

\section{INTRODUCTION}

Job satisfaction is a complex and multifaceted concept which can mean different things to different people. ${ }^{1}$ It is usually linked with motivation, but the nature of this relationship is not clear.It is considered more of an attitude, an internal state which could be associated with a personal feeling of achievement either qualitative or quantitative. ${ }^{2}$

The terms job satisfaction and motivation are often but wrongly used interchangeably in verbal (and often in written) communication, however there is a clear distinction between the two. Job satisfaction is a person's emotional response to his or her job conditions, whereas motivation is the driving

\section{Corresponding Author:}

Shilpa Khullar, E-605, front first floor, Greater Kailash part -2, New Delhi-110048.

E-mail:drshilpakhullar@gmail.com

ISSN: 2231-2196 (Print)

ISSN: 0975-5241 (Online)

DOI: $10.7324 / I J C R R .2017 .9185$

Received: 30.06 .2017 force to pursue and satisfy needs. However, job satisfaction and motivation work together to increase job performance and healthcare organizations can do many things to increase job satisfaction, primarily by focusing on the motivating interests of existing and future staff. ${ }^{3}$

Job satisfaction is one of the most widely discussed issues of today in terms of organisational behaviour, personnel and human resource management as well as organisational management. ${ }^{4}$ Simply stated it is the extent to which one feels good about one's job. ${ }^{4}$

There are three important features of job satisfaction. First, organizations should be guided by human values. Such organizations will be oriented towards treating work- 
ers fairly and with respect.In such cases the assessment of job satisfaction may serve as a good indicator of employee effectiveness. ${ }^{5}$ High levels of job satisfaction may be a sign of good emotional and mental state of employees. Second, the behaviour of workers depending on their level of job satisfaction will affect the functioning and activities of the organization's business. From this it can be concluded that job satisfaction will result in positive behaviour and vice versa, dissatisfaction from the work will result in negative behaviour of employees. ${ }^{5}$ Third, job satisfaction may serve as an indicator of organizational activities. ${ }^{6}$

In the health care field, attaining health objectives in a population depends to a large extent on the provision of effective, efficient, accessible, viable and high-quality services. The health workforce, present in sufficient numbers and appropriately allocated across different occupations and geographical regions is arguably the most important input in a unique production process that has a strong impact on overall health system performance. ${ }^{7}$ The lack of explicit policies for human resource management has produced, in most countries, imbalances that threaten the capacity of health care systems to attain their objectives. ${ }^{8}$

The workforce in the health sector has specific features that cannot be ignored and motivation can play an integral role in many of the compelling challenges facing health care today. ${ }^{9}$ In this area, the task of motivation is exacerbated by:

1. The nature of the economic relationship between those using the system and the system itself (physicians, patients and hospitals).

2. The heterogeneity of the workforce to be managed. In a teaching hospital, where doctors are playing dual role of teaching and patient care, this may have wider ramifications. The discontent of faculties may get translated into their academic output and may influence the morale and attitudes of medical students to the profession At the same time, poor job satisfaction of these physicians will adversely affect patient care. ${ }^{10}$

The medical faculty is critical to the infrastructure of any teaching institution. Attention to job satisfaction of medical faculty has gained national attention in part due to the current economic climate in which recruitment of faculty to replace those who leave is costly. Recent national survey data from the American Association of Medical Colleges (AAMC) reported a staggering $38-40 \%$ attrition rate of academic medical faculty over a ten-year period. Since faculty retention and job satisfaction are intimately linked, understanding what drives and satisfies academic medical faculty is invaluable for providing continuous and quality patient care, teaching the next generation of physicians, and minimizing the high cost of recruiting new faculty. ${ }^{11}$

Based on the proposed report of MCI undergraduate education working group 2010, the most significant challenge for regulatory bodies has been to balance the need for more medical colleges with the maintenance of quality standards .12

In this regard, the job satisfaction of medical teachers is perhaps not getting its due attention. It is a very important but very less studied issue. More work needs to be done to link the perception of individual faculty with the organizational context in which they work and with the wider political, economic, and social context of medical education reforms. This study was undertaken to construct the 'job satisfaction profile' of teaching faculty of a multispecialty teaching institution in India to evaluate their level of satisfaction and to describe variables related to their job satisfaction.

\section{The aims and objectives of the study were:}

- To ascertain the level of job satisfaction among faculty members of a tertiary care teaching institution of India.

- To determine the factors that influence 'job satisfaction' of faculty members.

- To determine factors leading to dissatisfaction among faculty members.

\section{MATERIALS AND METHODS}

This study was conducted at a medical teaching institution amongst its faculty members over a period of two months.

\section{Study population}

The study comprised of all the 64 faculty members of this college. The purpose of the study was explained to all the participants and written informed consent was taken from them before beginning of the project (copy of consent form enclosed). They subjects were informed that their participation is voluntary and they could withdraw from the study anytime they wished to do so.

Institutional Ethics Committee (IEC) approval was taken prior to the start of the study. The convenient sampling technique was used.

\section{Data collection tool - questionnaire design}

The study was conducted as an opinion survey among the faculty members based on a pre-structured questionnaire which was divided into two sections.

The questionnaire was designed to be simple, comprehensive and easily understandable by the faculty members.

The details of the questionnaire used were as follows:

Section 1 - socio-demographic features: age, sex, job title, duration of service with this organisation and type of employment. 
Section 2 - factors influencing job satisfaction: this section had six sets of questions exploring the various factors influencing an employees' satisfaction and his motivation level. There were total 19 statements numbered as S1 to S19

Factor 1 - professional practice environment (S1-S6)

Factor 2 - organisational factors of social support (S7-S8)

Factor 3- job competency (S9-S10)

Factor 4 - welfare measures offered by the organisation (S11-S14)

Factor 5 -job reward (S15-S17)

Factor 6 - motivation and work experience (S18-S19)

In addition, each faculty member was asked to give minimum two suggestions for improvement in their job satisfaction and motivation.

\section{Data collection method}

Initially the questionnaire was mailed at the official e-mail addresses of all the faculty members. They were informed verbally as well as through text messages that they had been mailed a questionnaire for this study. They were expected to download the questionnaire, give their responses and mail it back within a week's time, which would aid in maintaining the confidentiality and anonymity of the responses given by the subjects. However, after several reminders only 22 faculty members responded via mail which could be due to lack of internet facility in the college. A printout of the questionnaire was eventually given to the remaining faculty members who did not respond via E- mail.

\section{Technique used}

In terms of scaling, a five-point Likert scale was used (5highly satisfied, 4-satisfied, 3- neither satisfied nor dissatisfied, 2- dissatisfied and 1- highly dissatisfied).

An excel sheet was prepared to enter the data collected from the subjects. The mean score was calculated for each of the 19 statements along with the average mean score for all the statements combined. Based on the responses and suggestions given by the faculty members major satisfiers and dissatisfiers were identified.

\section{RESULTS}

The study was conducted on 64 faculty members of a medical teaching institution of different designations (Professor,
Associate professor and Assistant professor). The socio-demographic features of the study population can be seen in Table 1. Most of the subjects comprised of females $(56.25 \%)$ and Assistant Professors (53.12\%). Around 50\% of the subjects had been working in the organisation for 2-3 years and $2 / 3^{\text {rd }}$ had been recruited on a regular basis.

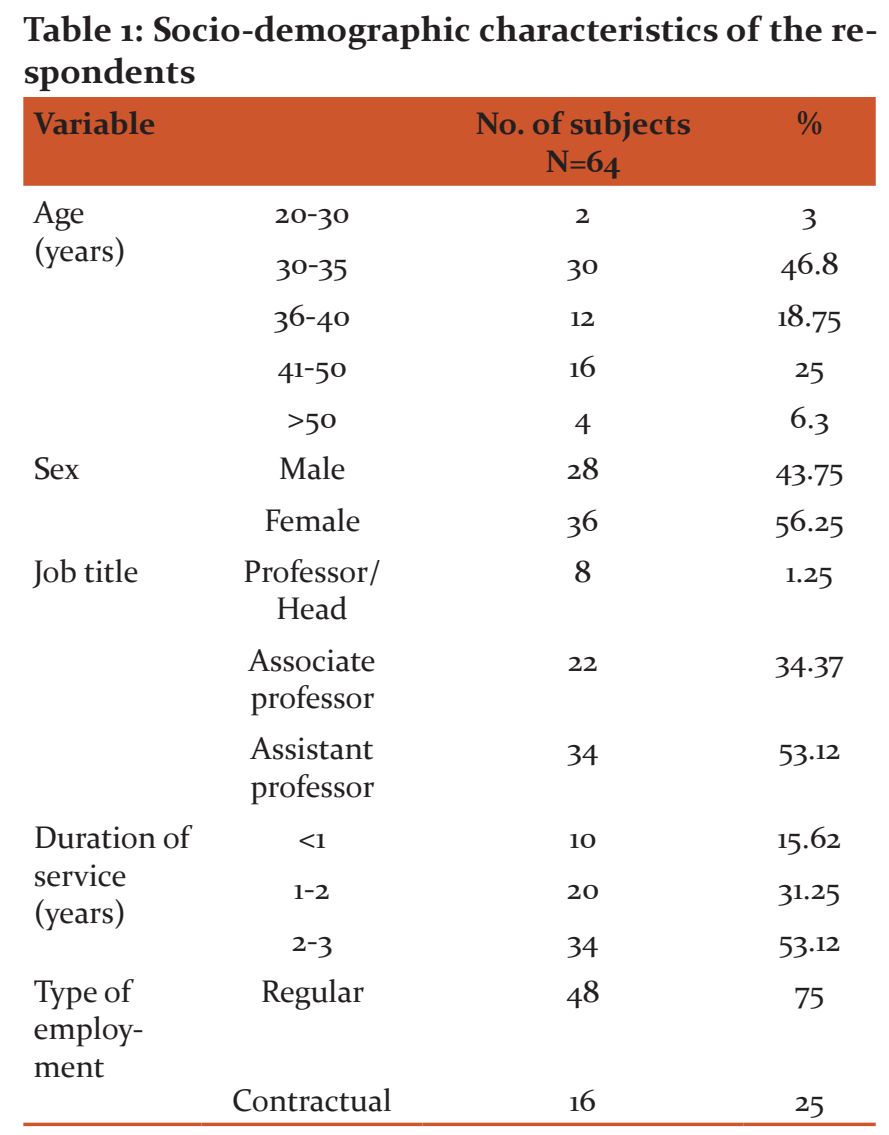

The overall satisfaction level of the faculty members was analysed based on statement No 18 of the questionnaire (S18). As can be seen in Table 2, 61\% of the faculty members seemed to be either highly satisfied or satisfied with their job currently, $84.5 \%$ were less than 40 years of age and around three quarters of them were females $(71.79 \%) .72 \%$ of the satisfied group comprised of Assistant Professor while remaining were of the rank of Associate professor and above. Those who had served the organisation for a shorter period $(<2$ years) seemed to be more satisfied than those who had worked longer than 2 years in the organisation. Around $90 \%$ of the satisfied groups was formed by regular staff while only $10 \%$ of the contractual staff seemed to be satisfied with their current position. 
Table 2: Socio-demographic characteristics of respondents satisfied with their job

\begin{tabular}{lccc} 
Variable & & $\mathrm{n}=39$ & $\begin{array}{c}\text { Percentage } \\
(\%)\end{array}$ \\
Age & $20-30$ & 13 & 33.3 \\
(years) & $31-35$ & 13 & 33.3 \\
& $36-40$ & 7 & 17.94 \\
& $41-50$ & 4 & 10.2 \\
Sex & $>50$ & 2 & 5.12 \\
& Male & 11 & 28.20 \\
Job title & Female & 28 & 71.79 \\
& Professor/ & 2 & 5.12 \\
& Head & & \\
& Associate & 9 & 23.07 \\
& professor & & \\
Duration of & Assistant & 28 & 71.79 \\
service & professor & & \\
(years) & $<1$ & 6 & 15.38 \\
Type of employ- & Regular & 35 & 89.74 \\
ment & Contractual & 4 & 10.25 \\
\hline
\end{tabular}

Table 3 lists the statements (S-1 to S-19) and the average scores received for each statement by all the faculty members (Figure 1). The range of average score for the facultywas 2.16 (S-17) to $4.05(\mathrm{~S}-5)$.

The teaching faculty seemed most satisfied with the teamwork and interpersonal relationships in the organisation (4.05), social schemes offered by the organisation (3.81) and considered themselves to be well equipped in terms of knowledge and skills as per their job expectations (3.90). They rated their performance to be high as per their job expectations (3.90).

All the subjects seemed to be dissatisfied with the loan facilities offered by the organisation (mean average score of 2.94) as well as with performance based incentives (mean average score of 2.16). They seemed dissatisfied with the promotion policy of the organisation (3.06).

Table 3: Mean scores of the faculty members for the various statements related to job satisfaction

$\begin{array}{ccc}\text { Statement No } & \begin{array}{l}\text { Statement } \\ \text { description }\end{array} & \begin{array}{c}\text { Mean score of all } \\ \text { the subjects }\end{array}\end{array}$

Professional practice environment

$\begin{array}{llr}\text { S-1 } & \begin{array}{l}\text { Adequate utilisa- } \\ \text { tion of skills }\end{array} & 3.35 \\ \text { S-2 } & \begin{array}{l}\text { Volume, variety } \\ \text { and quality of work }\end{array} & 3.75\end{array}$

S-3

Quality of supervi-

S-4 sion and feedback

by superiors

Opportunity for

personal growth,

development and

creativity

S-5

Interpersonal

relationship and

teamwork

S-6

Freedom for deci-

sion making

3.22

4.05

3.22

Organisational factors of social support

S-7

Organisational

culture fosters

3.66

recognition in the

workplace

S-8 Organisational

3.69

culture fosters

recognition in the

society

Job competency
S-9
S-10

How do I rate my

performance as per

job expectations

How well equipped

I am in terms of

knowledge and

skills as per job

expectations

Welfare measures

S-11

How do I rate my

work environment

$3 \cdot 46$

S-12

Health facilities

3.68

offered by my

organisation

S-13 Loan facilities

offered by my

organisation

S-14

Social security

schemes offered by

3.90

\section{Job reward}

S-15

my organisation

2.94

3.81

Promotion policy

of my organisation

3.06

S-16

Pay and allowances

$3 \cdot 75$

offered by my

organisation

S-17

Performance based

2.16

incentives

Motivation and work experience

S-18 Overall satisfaction level with the job

S-19

Visualising promis-

ing future for self

and the organisa-

tion 


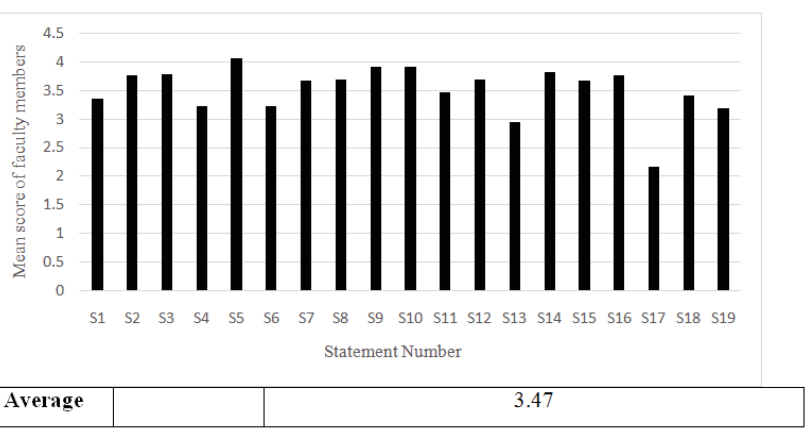

Figure 1: Mean score of faculty members for various statements from $\mathrm{S}_{1}$ to $\mathrm{S}_{19}$

Table 4 lists the comparative ranking of the various statements in the questionnaire, based on average scores of the responses. This can also be seen in Figure 2

Table 4: Comparative ranking of statements

\begin{tabular}{lc} 
Ranking & Statement number \\
$1^{\text {st }}$ & S-5 \\
$2^{\text {nd }}$ & S-9, S-10 \\
$3^{\text {rd }}$ & S- 14 \\
$4^{\text {th }}$ & S-3 \\
$5^{\text {th }}$ & S-2, S-16 \\
$6^{\text {th }}$ & S-8 \\
$7^{\text {th }}$ & S-12 \\
$8^{\text {th }}$ & S-7 \\
$9^{\text {th }}$ & S-11 \\
$10^{\text {th }}$ & S-18 \\
$11^{\text {th }}$ & S-1 \\
$12^{\text {th }}$ & S-4, S-6 \\
$13^{\text {th }}$ & S- 19 \\
$14^{\text {th }}$ & S- 15 \\
$15^{\text {th }}$ & S- 13 \\
16 th & S- 17 \\
\hline
\end{tabular}

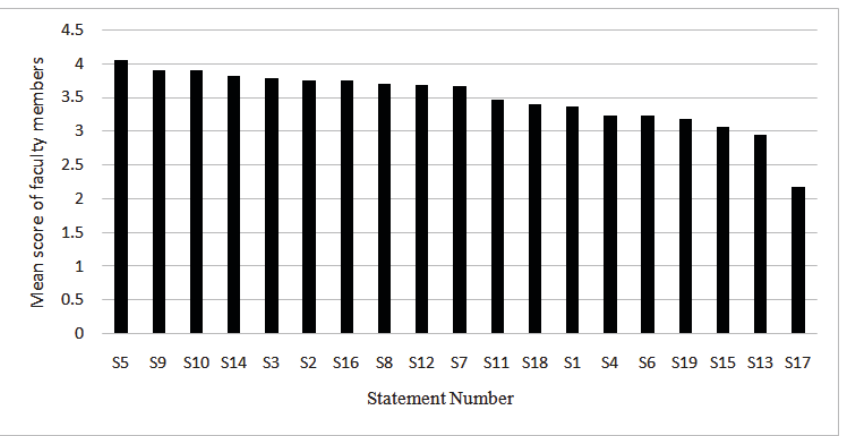

Figure 2: Comparative ranking of various statements from S1 to $\mathrm{S} 19$.

\section{DISCUSSION}

The present study was conducted at a medical teaching institution of India over a period of two months. It was done on all faculty members with the help of a pre-structured questionnaire. Most of the participants were young ( $<40$ years) and majority of the staff members were females $(62.5 \%)$.

Various studies have established that dissatisfaction with one's job may result in higher employee turnover, absenteeism, tardiness and grievances. Improved job satisfaction, on the other hand, results in increased productivity and efficiency. ${ }^{12}$

Since job satisfaction has a strong correlation with job performance, it is imperative to reinforce relevant human resources policies, improving working conditions and compensation. It recommends that priority should be given to improving working relationship between management and staff and increasing decision making attitude among staff members. A similar study was conducted on same number of subjects as ours recently among doctors in a tertiary care hospital in Chhattisgarh. The study population was divided into three categories: clinical, para-clinical and non-clinical. Like our results many respondents had a short duration of service of less than 2 years (42. $2 \%$ ). More than $50 \%$ of the subjects felt that they enjoyed their work and were satisfied with their work profile. $64 \%$ of the subjects agreed that there were sufficient opportunities for self-development, while most agreed that they received sufficient recognition at their workplace. Like our study, a good majority shared a good working relationship with their colleagues. ${ }^{13}$

A study was done in USA to assess the work environment to identify characteristics that could increase faculty retention valuable to the health of the educational institutions. It involved 38 institutions and 451 full time faculty members. Positive satisfaction aspects of work environment listed by the respondents included supportive administration, working relationship with colleagues and interaction with students. Negative satisfaction aspects of the work environment included low salary, long working hours and a heavy workload. Both positive and negative aspects related to job-satisfaction need to be analysed within framework of each institute to enact change for career enrichment leading to increased career recruitment and retention. ${ }^{14}$

Age has a positive and significant relationship with job satisfaction, commitment and job involvement in our findings. In the context of other research, the results do suggest the influence of age in public sector, with older employees more likely to be satisfied with and involved in their work. This finding is consistent with the growing human capital crisis resulting from the "greying" of government. ${ }^{15}$ Younger employees seem less interested in or satisfied with government work. One possibility is that older workers' sense of job sat- 
isfaction is formed by a longer time-span that covers eras in which public service was held in high esteem.

The findings on negative effect of length of time in the same position, along with the findings on the importance of promotional opportunities suggest the critical importance of promotions to reduce the stultifying effect of being in the same position. Even in our study it has been seen that lack of promotions was a major dissatisfier. Assistant professors that were recruited in 2011 are yet to be promoted even after 5 years of regular service, whereas they were promised promotion after 2 years of regular service to the higher post of Associate Professor at the time of recruitment. There is no clarity regarding the promotion policy of the organisation which was a major point of dissatisfaction among the faculty members.

The opinion of the respondents about their professional practice environment has been tabulated in Table 3. Many of the subjects thought that their job utilises their skills adequately and seemed to be satisfied with the volume, variety and quality of work that their job had to offer (3.75). The faculty seemed to be satisfied with the quality of supervision and feedback given by their superiors and were happy with the inter-personal relationships and teamwork within the organisation (4.05).

A study was undertaken on the job satisfaction profile among Serbian healthcare workers who worked with disabled patients. The result found very low levels of job satisfaction among healthcare workers. The study concluded that job satisfaction was associated with good hospital politics, good interpersonal relationships and a feeling of being enabling to provide good quality care. ${ }^{16}$ Other studies suggest that there is a strong association between low levels of job satisfaction and organizational factors. Furthermore, various studies conducted among healthcare workers show the importance of interpersonal relationships in job satisfaction as has been seen in our study also. ${ }^{17}$

Buciuniene et $\mathrm{al}{ }^{18}$ conducted a study on the job satisfaction of physicians and general practitioners at primary health care institutions during the period of health care reforms in Lithuania. Doctors who had a longer service were found to be more satisfied with their jobs. The survey also showed that the participants were most satisfied with the level of autonomy, relationship with colleagues and management quality as has been seen in our study also, while compensation, social status and workload caused the highest level of dissatisfaction among respondents.

Numerous studies conducted among healthcare professionals point to the importance of interpersonal relationships in job satisfaction, and that good interpersonal relationships lead to increased patient safety, improved quality of care and greater patient satisfaction. The human relations school questioned this view, and evidence has accumulated that a monotonous and dull task environment alienates employees. Employees who experience greater variety in their day-to-day work have been shown to be less likely to lose interest in their job and become bored and are likely to be more satisfied. ${ }^{19}$

The mean average score of faculty members regarding organisational culture fostering recognition in the workplace and society was 3.67. Employee commitment indicates the sense of loyalty and obligation the employee holds toward the organization. ${ }^{20}$

Recent work from Harrison, Newman and Rothsupports this perspective, arguing that variables such as job satisfaction and organizational culture overlap a good deal and could be collectively considered when examining employee attitudes and behaviour. ${ }^{21}$

Most of the faculty seemed to be satisfied with their work environment as well as with the health facilities and social security scheme offered by the organisation (Table 3). They were not happy about the loan facilities offered by the organisation.

Employee participation can afford individuals an opportunity to make key managerial decision that have an impact on other employees, thus increasing job satisfaction and performance.

We found that rating of environment was very important, which is evident from the thinking of employees who wanted to have a good relationship with their co-workers, to be able to talk about something else other than the work sometimes, to have fun together and not just to work. In addition, it was argued that the employees depend mostly on their co-workers and spend more time with them at work than with their families, sometimes more than 48 hours a week. Therefore, it is important to feel comfortable with work colleagues, no matter the type of work. ${ }^{22}$

A very high percentage of employees seemed satisfied with the pay and allowances (mean scoring 3.75 ) that their job had to offer compared to few being happy with the performance-based incentives (mean average score-2.16).

Managers in the government sector have limited tools by which they may motivate and retain their employees, since strict service rules and standard pay grades limit the ability to recognize and reward individuals through pay, promotion, or bonuses in the government sector.

Achievement as an intrinsic factor, has found to be the main motivator in both the doctor and nurse subgroups. Thus, delegation of authority, recognition of personnel efforts, opportunities for promotion and the job enrichment must be a part of the hospital human resource strategy. ${ }^{23}$ Similar ideas were given by our subjects also. 
A study was conducted to determine job satisfaction of dental faculty with their role of teaching and research in academic institutions of India. It involved 341 faculty members from 139 dental institutes. Most of the respondents were satisfied with their teaching and service items. Neutral responses were made for institutional teaching rewards, institutional financial support for research, release time offered by the institution, support for sabbatical leaves, technical assistance in analysing data, secretarial and technical assistance, institutional research rewards, in-service training opportunities, and institutional service rewards. Dissatisfied responses were made regarding financial and academic support for making scientific presentations and attending conferences and seminars as was seen in our study also. ${ }^{24}$

As can be seen in Table 3 many of the faculty members were satisfied with their job for the time being (mean average score -3.40 ) and visualised a promising future for the organisation and for themselves (mean average score -3.18).

\section{Limitations of the study}

- Only faculty members were a part of this study while other types of staff working in the college (technical, clerical, nursing, cleaning etc) have been excluded.

- Although the faculty was assured of complete confidentiality and anonymity about their responses, it is still likely that they have under or over reported their satisfaction level for fear of information reaching the Head of the Department/institution

- Some of the participants did not see any value in being part of the study. They might view the results as being too sensitive and may be suspicious of the underlying motive of the research

- The findings of the study may not be generalised to other medical/dental colleges due to difference in environment and circumstances prevailing in other colleges which have an impact on job satisfaction

\section{CONCLUSION}

Around $61 \%$ of the subjects seemed to be satisfied or highly satisfied with their current job. Majority of them were females, less than 40 years of age and had been recruited on a regular basis. People who had worked in the organisation for less than 2 years were generally more satisfied. The major factors contributing to job satisfaction and employee motivation included: nature of interpersonal relationship and teamwork among co-workers and social security schemes offered by the organisation. They rated their performance high as per their job expectations and considered themselves to be well equipped in terms of knowledge and skills as per their job expectations. The satisfied group felt that the organisational culture fosters recognition in the workplace and society. The major causes of dissatisfaction included: lack of performance based incentives, loan facilities offered by the organisation and the promotion policy of the organisation

\section{ACKNOWLEDGEMENT}

Authors acknowledge the immense help received from the scholars whose articles are cited and included in references of this manuscript. The authors are also grateful to authors/ editors/publishers of all these articles, journals and books from where the literature for this article has been reviewed and discussed

\section{Source of funding: Nil}

\section{Conflict of interest: Nil}

\section{REFERENCES}

1. Usop AM, Kadtong ML, Amir D, Usop SO. The significant relationship between work performance and job satisfaction in Philippines. International Journal of Human Resource Management and Research 2013;3(2):9-16.

2. Mullins JL.Management and organisational behaviour. $7^{\text {th }}$ ed. Essex:Pearson Education Limited; 2005.

3. Griffeth R, Hom PW, GaertnerS.aMeta-Analysis of antecedents and correlates of employee turnover: update, moderator tests and research implications for the Millennium. Journal of Management 2000; 26 (3):463-488.

4. Ali T. Job satisfaction of faculty members in private universities - in context of Bangladesh. International Business Research 2009;2(4):167-175.

5. Venkatesh K. Job satisfaction among primary school teachers with respect to age, gender and experience. The International Journal of Indian Psychology 2016;3(2):89-94.

6. Aziri B. Job satisfaction: a literature review. Management research and practice 2011;3(4): 77-86.

7. Rigoli F, Dussault G. The interface between health sector reform and human resources in health. Human Resource for Health 2003;1(1):9.

8. Dussault G, Dubois CA. Human resources for health policies: a critical component in health policies. Human Resource Health 2003;1(1):1.

9. Lambrou P, Kontodimopoulos N, Niakas D. Motivation and job satisfaction among medical and nursing staff in a Cyprus public general hospital. Human Resources for Health 2010; 8:26.

10. Bhatnagar K, Srivastava K, Singh A, Jadav SL. A preliminary study to measure and develop Job satisfaction scale for medical teachers. Industrial Psychology Journal 2011; 20(2): 91-96.

11. Chung KC, Song JW, Kim HM, Woolliscroft JO, Quint EH, Lukacs N, at al. Predictors of job satisfaction among academic faculty members: do instructional and clinical staff differ? Med Educ2010;44(10):985-95.

12. Medical Council of India. Proposed under graduate medical education, undergraduate education working groups. India; 2010. Available from: http://www.bvnmedicol.org/uploaded_files/ug medical-education.pdf.

13. PandeyS, Gahwai D, Manwani VK. Study of job satisfaction and work environment perception among doctors in a tertiary care hospital in Chhattisgarh, India. Indian Journal of Scientific Research 2014;3(1):361-364. 
14. Froeschle ML, Sinkford JC. Full-time dental faculty perceptions of satisfaction with theacademic work environment. Journal of Dental Education 2009 ;73(10):1153-70.

15. Moynihan DP, Pandey SK. The role of organisation in fostering public service Motivation. Public Administration Review2007;67(1):40-53.

16. Rainey HG, Steinbauer P. Galloping elephants: developing elements of a theory of effective governance organisations. Journal of Public Administration Research and Theory1999;9(1):1-32.

17. Mahmoud Al-Hussami RN. A study of nurses' job satisfaction: the relationship to organisational commitment, perceived organisational support, transactional leadership, transformational leadership and level of education. European Journal of Scientific Research2008;22(2) :286-295.

18. Buciuniene I, Blazeviciene A, Bliudziute E. Health care reforms and job satisfaction of primary health care physicians in Lithuania. BMC Family Practice2005; 6:10.

19. Wright BE, Davis BS. Job satisfaction in the public sector: the role of the work environment. American Review of Public Administration2003; 33(1):70-90.
20. Allen NJ, Meyer JP. The measurement and antecedents of affective, continuance and normative commitment to the organisation. Journal of Occupational and Organisational Psychology 1990; 63:1-18.

21. Harrison DA, Newman DA, Roth PL. How important are job attitudes? meta-Analytic comparisons of integrative behavioural outcomes and time sequences. Academy of Management Journal2006;49(2):305-325.

22. Jain M, Mathur A, Joshi S, Goklani P, Kothari B, Prabhu D, et al. Job satisfaction assessment among dentists and dental auxiliaries in India. Internet Journal of Dental Sciences2009; 7(2).

23. Byrne M. The implications of Herzberg's "motivation-hygiene" theory for management in the Irish health sector. Health Care Manag2006; 25(1):4-11.

24. Shigli K, Hebbal M Nair KC. Teaching, research and job satisfaction of Prosthodontic faculty members in Indian Academic Dental Institutions. Journal of Dental Education 2012;76(6):783791. 